\title{
Spatial Visualisation of Correlations Between Key Innovation Factors: Standardisation Activities, Intellectual Property Activities and R\&D Activities in the Japanese Electric Machinery
}

\author{
Suguru Tamura \\ Waseda University, GITS/Comprehensive Research Organization \\ Nishi-waseda Shinjuku-ku, Tokyo, Japan
}

\begin{abstract}
This paper examines the spatial visualisation of the relationships amongst three factors viz., standardisation related activities, intellectual property related activities and $R \& D$ activities. The inverse of the correlation coefficients between each pair among the three factors is used to measure the distances graphically. This is expressed by a 'triangle-shaped model.' For the electric machinery industry in Japan, these three factors form more compact triangles when, compared with all industries in Japan. The difference in the shape of the triangles reflects the closeness among the three factors, especially in terms of standardisation in these industries. This methodology is expected to be useful for establishing robust and comprehensive technology management systems for corporate $R \& D$ activities. Such technology management systems can allow for the protection of proprietary $R \& D$ information and promote information gathering during standardisation activities.
\end{abstract}

Keywords: Triangle shaped model, standardisation, $R \& D$, distance.

\section{INTRODUCTION}

7 his paper aims to study the graphical expression of relationships amongst three factors viz., (1) standardisation activities, (2) intellectual property (IP) activities and (3) R\&D activities. To this end, the notion of 'distance' between the three factors is newly introduced. This methodology has not been used before. Statistical relationships amongst standardisation activities, IP activities and R\&D activities within organisations in the Japanese electric machinery industry are used for input data. The key motivation is to develop evidence based numerical methods such as correlation analysis for the study of standardisation, rather than empirical explanation, which have been normally applied until now. Raw data from a survey conducted by the Japan Patent Office in the 2008 is used (Japan Patent Office, 2008).

Digitisation started in the late 1990s and its influence has spread rapidly in the past decade. In this regard, the key phenomena are the emergence of digital appliances and the Internet. Due to changes in the business environment, the
Journal of Technology

Management for Growing Economies

Vol. 4 No. 2

Oct 2013

pp. 7-30

\section{ChITKARA 司 \\ UNIVERSITY}

C 2013 by Chitkara University. All Rights Reserved. 

more standardisation oriented than other industries. In addition, the field of information and communications technology (ICT) is experiencing the rapid merging of patents and standards; therefore, the evaluation of standards' effects on patent and IP activities is becoming an important policy issue (Ministry of Economy, Trade and Industry (METI) and Mitsubishi Research Institute, 2009). China-US dialogue about the patent-embedded standards is one such policy case (Tamura, 2012a).

Even in the 21 st century, research on standardisation from the viewpoint of graphical and statistical assessment and analysis is surprisingly still a new emerging area, primarily because of lack of data. Only recently, the quantitative data on labour force relating to standardisation activities were assimilated (Tamura, 2012b). Consequently, quantitative analysis has been impossible for researchers. Elsewhere, the government patent agencies in China and South Korea are gathering information about patent activities. Yet, there is no attempt to gather information about standardisation in corporations. Conversely, in Japan, beginning in 2008, the Japan Patent Office added a new survey question to capture input data on standardisation-related activities. Specifically, the number of persons engaged in IP-related activities along with standardisation activities is counted.

The Japan Patent Office's statistical survey, The Survey of Intellectual Property-Related Activities (SIPRA), which started in 2002, originally aimed at monitoring the trends in IP activities. The survey covers input and output factors affecting the IP-related activities of the corporations. For example, on the output side, the survey includes the number of patent applications submitted. On the input side, the report provides information on human resource participation in R\&D activities, IP activities and so on.

As background information, the reason why data on standardisation activity are scarce is that a measurement methodology for standardisation is not well established. One of problems in measuring corporate standardisation is that these tasks are usually carried out by staff as supplementary work in addition to their main duties. Therefore, standardisation activities are 'invisible' from the outside and even from the inside, from the perspective of senior management. This state of affairs hinders the recognition of standardisation activity in corporations.

At present, the studies on standardisation issue in science and innovation policy forums, such as the Organisation for Economic Co-operation and Development (OECD), which concentrate on researching IP issues, such as patents are insufficient. In addition, public international standard development organisations (SDOs) such as the International Organization for Standardization 
and the International Telecommunication Union mainly focus on developing standards themselves rather than evaluating standardisation activities. The data gathered by these organisations cover narrow areas such as the number of standard stipulations, as they do not have a duty to study standardisation related activities in corporations.

Unlike the relationships between IP strategy and corporate innovativeness, and between R\&D and corporate innovativeness, and between standardisation and corporate innovativeness, has not been well illustrated due to the aforementioned factors. A famous case where a standard impedes product innovation is the QWERTY keyboard (David, 1985). The lock-in effect of the QWERTY keyboard arrangement hindered the introduction of a more speed oriented key arrangement by Apple Inc. The standardisation by committees or SDOs has not been widely examined from a research perspective (Steinfield et al, 2007). This is because the concepts and notions of standardisation are considered difficult to understand and that numerical expression of standardisation is not fully established methodologically.

Another reason why the relationships amongst factors affecting standardisation are still difficult to grasp is that, in addition to a lack of data, the academic community has not attempted visualisation. In the current research, the distances between different patents have been calculated to demonstrate technological similarity or dissimilarity. This approach uses the concept of 'distance in technology space', which measures the distance between IP (patents) and technology (R\&D). This method is useful to analyse technology development trends at the national, corporate and university levels (Jaffe and Trajtenberg, 2002 ).

In light of the above discussion, this research uses the distances amongst innovation-related factors (IP, standardisation and R\&D) as methodology towards potentially gaining a deeper understanding of these relationships among the factors. It is understood that this research faces numerous challenges and is in its infancy. Thus, it needs further development and elaboration, but this first step is worthwhile as a starting point for future development of a visualisation method for analysing standardisation. The basic concept of the graphical expression method proposed is the triangle-shaped model (TSM). This may prove useful in the development of this research area. In the past century, patents and standards were different enough such that it was sufficient for $R \& D$ management to consider the two elements differently for analysing technology trends. However, in the 21 st century the roles of the two elements are overlapping because of rapid development in ICT (METI and Mitsubishi Research Institute, 2009). Moreover, the development of ICT is penetrating every aspect of the social sphere. For example, at the start of the $21^{\text {st }}$ century, the

Journal of Technology Management for Growing Economies, Volume 4, Number 2, Oct 2013
Visualisation of

Correlations 

in essence neither tangible, nor transferable or conservable. This implies that service quality largely depends on each person's experience and accumulated knowledge and skills. However, the quality and management of the service industry has changed drastically because of advances in ICT. Today, in large parts of the services industry, ICT is the core technology and the conventional nature of the services industry is changing. As seen at the national level in Finland, development of the ICT industry is strongly connected with technological development at the national level (Tokumasu and Watanabe, 2008). In this case, the role of the ICT industry was strongly linked with the development of technology standards. Hence, in coming decades, methods to express the relationship between standardisation and other factors are likely to become an essential academic discipline.

This research introduces a graphical expression method to illustrate the numerical relationship amongst innovation factors. Correlation levels are compared while considering the causes. In this analysis, regarding standardisation activities, IP related standardization activities are used as a proxy for all standardisation related activities. This means that the number of persons engaged in IP related standardisation activities is used as a proxy for the number of persons engaged in standardisation related activities. To evaluate the effect of standardisation related activities, it would be preferable to use the number of persons engaged in standardisation related activities directly, but the level of standardisation related activities in corporations is not obtained in the data source i.e., SIPRA. The number of the persons engaged in these activities is used as the measure for IP-related activities and are provided on a full-time equivalent (FTE) basis.

Furthermore, the concept of 'distance' between standardisation, IP and $\mathrm{R} \& \mathrm{D}$ is proposed to evaluate the relationship of these factors. In addition, relationship between these three factors is presented in graphical form. This methodology of showing relationships graphically has been used in various areas of innovation studies. A graphical presentation is easier to understand than just a numerical expression, and may be useful in helping researchers generate new ideas. A novel methodology to show the relationships is the TSM, where the notion of 'distance' between the factors is introduced to represent statistical information in graphical form. In the proposed TSM, the Pearson correlation coefficient is used as the basis to calculate the distance between two factors. The distance is analogised as the side of the triangle; the shape of the triangle will be determined by the length of the sides. The degree to which the three factors are related is represented in the shape of the triangle. 


\section{RESEARCH OBJECTIVES}

The research objectives of this paper are as follows-

Objective 1: To develop a spatial visualisation method which illustrates the relationship amongst three factors - standardisation activities, IP activities and $\mathrm{R} \& \mathrm{D}$ activities.

Objective 2: To examine the validity and implications of the spatial visualisation method as applied to the electric machinery industry in Japan.

An all industries dataset is used for comparison. The electric machinery industry is heavily involved in providing ICT services, and is thought of as a good proxy for examining the impact of standardisation on an industry.

The contents of this paper are as follows. The next section provides a review of the literature, which focuses on examining the relationship of prior research with this paper, which includes the hypotheses and their backgrounds. This is followed by methodology of TSM analysis and the composition of the dataset used. Further, the results of the analysis and discussion of the results is presented. Then, the conclusion and the limitations of this research paper are provided. Abbreviations used in this paper are listed after the conclusions.

\section{LITERATURE REVIEW}

This research is based upon the following content and frameworks in previous research and documents. However, research in this area is still under development, so relevant documents are scarce.

\section{Visualisation}

Visualisation transforms raw data into graphical forms so that people can understand quickly (Lohse et al, 1990). For instance, in high profile international scientific research projects involving multiple nations, visualisation plays the key role in knowledge discovery (Ma, 2007). Visualisation can help overcome communication gaps and transmit knowledge. Visualisation of the network structures of R\&D partnerships is the one of the most important streams in the study of science and innovation (Gay and Dousset, 2005; Roijakkers and Hagedoorn, 2006).

Moreover, for corporate innovation, a positive effect of visualisation can be recognised. One example is three dimensional computer aided design systems, which allow various aspects of design to be visualised. The visualisation of modelling in product development enables designers and engineers to engage in more advanced hypothesis formulation and support an engineer's abduction process (Baba and Nobeoka, 1998). From a practical viewpoint, it is reported that the number of trial parts prepared in the development of a jet liner

Journal of Technology Management for Growing Economies, Volume 4, Number 2, Oct 2013
Spatial

Visualisation of Correlations 

process (Baba and Nobeoka, 1998).

Nevertheless, in the current research stream, the data used for visualisation are mainly from R\&D alliance data and other such sources and the factors affecting standardisation are not within the scope of this data.

\section{Defining technological 'distance'}

Conventionally, technological distance is defined by Jaffe (1986) using a vector composed of the number of patent applications in a certain technological area.

For example, such a vector may be expressed as follows:

$P_{i j}$ shows technological distance: $P_{\mathrm{ij}}=\frac{F_{i} F_{j}}{\sqrt{\left(F_{i} F_{j}\right)\left(F_{i} F_{j}\right)}}$

Using the methodology in the field of solar cells the technological distance between Canon and Panasonic is calculated as 0.681 while the distance between Canon and foreign corporations is 0.796 . This implies that, in terms of R\&D, Canon is more similar to Panasonic than to foreign corporations (Kohmoto et al, 2009). However, the distance definition does not consider standardisation as a factor at all.

Standardisation activities, IP activities, $R \& D$ and corporate innovativeness

There are few studies on the relationship between corporate innovativeness and standardisation within corporations from an econometric perspective. However, standardisation activities have been shown to have a positive correlation with patent applications in the electric machinery industry in Japan (Tamura, 2010). Standardisation is treated as a possible innovation factor, which has a positive impact. In addition, for SDOs rather than corporations, the work of Gandal et al (2007) shows that there is a significant positive correlation in the electric machinery industry in the United States between the level of participation in an SDO and the number of patents granted for electric modem products. This conclusion was reached by observing patents granted between 1970 and 1990 and related participation in the SDO meetings from 1990 to 1999 . This research looked at standard TR-30 of the Telecommunications Industry Association in the United States. The main US participants in TR-30 are AT\&T, Motorola, 3COM (Gandal et al, 2007). The implication of this previous research for the present research is that quantitative analytical methods are applicable to evaluate standardisation. In addition, the relationships of R\&D and IP activities to innovation are recognised as being typically positive (Acs and Audresch, 1989), and these two factors are generally considered to be innovation factors 
as well. In sum, standardisation activities, IP activities and R\&D activities are defined as possible innovation factors in scope of this research.

An interview based survey of corporate personnel engaged in $R \& D$ revealed the wide spread opinion that, compared with academic research papers, standards have a greater impact on industry (Tamura and Matsuda, 2008). This means that for corporate R\&D strategy, information on the formulation of new standards is as important as R\&D activities. These previous studies explicitly suggest that standardisation related activities; $R \& D$ and patent applications have a strong correlation with each other.

\section{HYPOTHESES}

In this research, the following hypotheses are examined.

Measuring the degree of integration amongst three factors: $R \& D$, IP-related standardisation activities and IP-related activities.

Hypothesis 1: There is a positive and significant degree of correlation between R\&D activities, IP-related standardisation activities and IP-related activities.

This hypothesis is examined using three sub-hypotheses (1a, 1b and 1c) for relationship analysis. Among the past research works there is no study, which focuses on the relationship between R\&D activities and IP-related standardisation activities. The relationship between the IP-related activities and IP-related standardisation activities is discussed by only Tamura (2010) in a two-factor model. For logical consistency, a check against previous research results from Tamura (2010) is made. For hypothesis 1c, it is anticipated that IP-related standardisation activities and IP-related activities have a positive relationship, in line with Tamura (2010).

Hypothesis 1a: The correlation between R\&D and IP-related standardisation activities is significant and positive.

This hypothesis is tested to determine the relationship between IP-related standardisation activities and R\&D activities. Based on the current state of knowledge, the relationship is not clear from a quantitative viewpoint because the question as to whether $\mathrm{R} \& \mathrm{D}$ activities are positively associated with standardisation activities has not been discussed in the literature previously. If the result is positive and significant, these two factors are understood to be associated and integrated with each other.

Hypothesis 1b: The correlation between R\&D and IP-related activities is significant and positive.

This hypothesis is tested to determine the relationship between IP-related activities and R\&D activities. It is anticipated that both the factors will show a

Journal of Technology Management for Growing Economies, Volume 4, Number 2, Oct 2013
Visualisation of

Correlations 

the number of persons involved in IP-related activities and the number of persons involved in $R \& D$ is calculated. If the result shows a significant positive relationship, R\&D activities will be understood as associated with corporate IP activities.

Hypothesis 1c: The correlation between IP-related activities and IP-related standardisation activities is significant and positive.

This hypothesis is tested to determine the relationship between IP-related standardisation activities and IP-related activities in a three-factor framework rather than the two-factor framework used in previous research works. A positive result would illustrate this research's consistency with the previous research analysis using only two factors.

Comparison of correlations amongst $R \& D$, IP-related activities and IP-related standardisation activities between all industries and the electric machinery industry in Japan

Integration amongst the factors (based on distance) is supposed to be closer in the electric machinery industry than in all industries. The following hypothesis is set to examine the degree of standardisation in different industries.

Hypothesis 2 : Distances between the factors are more equal and the triangle shape of the three factors is more regular in the Japanese electric machinery industry than in all industries.

This hypothesis means that the electric machinery industry is more standardisation oriented than all industries. To validate Hypothesis 2, 'distance' and 'shape' of the graphical representations can be compared.

\section{METHODOLOGY}

The correlations between the three factors are calculated (i.e., by using the numbers of persons engaged in IP-related activities, IP-related standardisation activities and R\&D) for the electric machinery industry and all industries in Japan. Figure 1 provides an analytical framework of the relationships between these three factors. In addition, t-tests were conducted at the significance levels of $5 \%, 1 \%$ and $0.1 \%$. All calculations for correlation coefficients were performed with the statistical analysis tools of Microsoft Excel 2010. The methodology comprising of (1) graphical model expression using the TSM, (2) quantifying the factors, (3) counting methodology, (4) dataset construction and (5) definitions is explained in the following paragraphs. 


\section{IPRA}

Intellectual property-related activities (PIPRA)
(2)

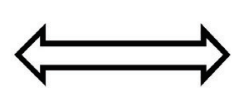

$\underline{\mathrm{R} \& \mathrm{D}}$

(3)

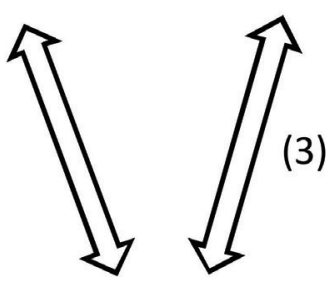

Spatial

Visualisation of Correlations

(1)

\section{IPRSA}

Intellectual property-related

standardisation activities (PIPRSA)

Figure 1: Analytical framework for 'distance' evaluation in triangle -shaped model (TSM)

\section{Graphical Model Expression: Notion of 'Distance' between Factors}

In order to understand the position intuitively, a methodology to show distances between the three factors is proposed. Here, the notion of distance is defined in the following conversion formula.

Definition: distance $=\frac{1}{\text { Pearson correlation coefficient of two factors }}$

In the conversion, the Pearson correlation coefficient is used. In this analysis framework, comparing the factors is valid because the dimensions and units used in each factor are the same. The measured quantity of each is 'number of persons.'

In everyday life, the notion of closeness means a short path; hence a number representing closeness should be small. In the case of the Pearson correlation coefficient, the larger the number is, the closer the correlation. Thus, to invert the relationship, the Pearson correlation coefficient is used for further analysis by calculating its inverse. The resulting numbers will enable the visualisation of the relationships amongst the three elements viz., IPrelated activities, IP-related standardisation activities and R\&D. The inverted Pearson correlation coefficients become the lengths of the sides of the triangle. A shorter distance means a closer correlation and vice versa. In this paper, this concept is encompassed in the TSM. 
Tamura, S.

In the TSM, each edge represents the statistical closeness of factors. For comparison purposes, the distance between R\&D and IP-related activities is set as 1 and the other two sides between R\&D and IP-related standardisation activities, and IP-related activities and IP-related standardisation activities are divided by the distance between R\&D and IP-related activities. Hence, the other sides are expressed as multiples of the length of the side comprising of $R \& D$ and IP-related activities. The multiples are defined as 'comparative distance' (CD):

Comparative Distance 1: CD1 $=\frac{\text { Distance between } R \& D \text { and IPRA }}{\text { Distance between } R \& D \text { and IPRA }}=1$

Comparative Distance 2: $\mathrm{CD} 2=\frac{\text { Distance between } R \& D \text { and IPRSA }}{\text { Distance between } R \& D \text { and IPRA }}$

Comparative Distance 3: $\mathrm{CD} 3=\frac{\text { Distance between IPRA and IPRSA }}{\text { Distance between } R \& D \text { and IPRA }}$

For comparison amongst different industry sectors, the value 'relative correlation' (RC) is introduced. RC compares the distance between R\&D and IP-related activities amongst industry sectors by comparing their Pearson correlation coefficients.

$$
\mathrm{RC}=\frac{\text { Pearson correlation coef ficient of } R \& D \text { and IPRA in an industry sector }}{\text { Pearson correaltion coef ficient of } R \& D \text { and IPRA in all industries }}
$$

Therefore, in this research covering all industries and the electric machinery industry, we calculate $\mathrm{RC}$ as follows:

$$
\mathrm{RC}=\frac{\text { Pearson correlation coef ficient of } R \& D \text { and } I P R A \text { (electric machinery industry) }}{\text { Pearson correlation coef ficient of } R \& D \text { and IPRA (all industries) }}
$$

$\mathrm{RC}$ shows the relative compactness for factor correlations in an industry (as represented by a triangle) versus all industries.

\section{Quantifying the Factors}

IP-related standardisation activities are used as a proxy for the quantity of standardisation-related activities. To evaluate the effect of standardisation related activities, it would be preferable to use the number of persons engaged in standardisation-related activities directly, but the level of standardisation related activities in corporations is not obtained directly in the data source (SIPRA). The number of the persons engaged in the activities on FTE basis is used as the amount for IP-related activities. The number of persons engaged in $R \& D$ activities is used for $R \& D$ to ensure consistency with the other factors.

\section{Counting Method}

Estimates of the numbers of persons engaged in IP-related standardisation activities, IP-related activities and R\&D is taken. SIPRA counts the numbers

Journal of Technology Management for Growing Economies, Volume 4, Number 2, Oct 2013 
of persons engaged in IP-related standardisation activities, IP-related activities and R\&D on FTE basis, rather than using headcount of persons involved in these activities. The FTE method more accurately reflects how much labour is engaged in the activity. In addition, counting researchers and scientists on an FTE basis is recommended in the OECD Frascati Manual (OECD, 2002).

\section{Dataset Construction}

The datasets were prepared using raw data from the SIPRA for 2008 according to the following guidelines (Tamura, 2010).

(i) Data concerning individuals other than those working in organisations were removed from the dataset, as the purpose of this research is to examine effects within organisations.

(ii) Data were included in the dataset only if there were complete data for all four factors (patent applications, the number of persons engaged in IPrelated activities, the number of persons engaged in IP-related standardisation activities and R\&D). Observations with incomplete data were disregarded.

(iii) Data were removed from the dataset if the number of persons engaged in IP-related standardisation activities was larger than the number of persons engaged in IP-related activities. These data are likely the result of completion error by respondents. The intention of the SIPRA is to ask how many persons are engaged in standardisation-related activities as part of the category of IPrelated activities. Therefore, the number of standardisation-related activities within IP-related activities should be smaller than that of IP-related activities.

\section{Data Definitions}

Data is gathered based on the following definitions in the SIPRA:

Table 1: Terms and Definitions

\begin{tabular}{|l|l|}
\hline \multicolumn{1}{|c|}{ Terms } & \multicolumn{1}{c|}{ Definition } \\
\hline Standardisation & $\begin{array}{l}\text { Specifications that determine the compatibility of different products. } \\
\text { (Stango, 2004) }\end{array}$ \\
\hline $\begin{array}{l}\text { Standardisation- } \\
\text { related activities }\end{array}$ & $\begin{array}{l}\text { 1. 'The formation of standards or amendments to a certain technology } \\
\text { among multiple relevant parties.' } \\
\text { (Under this definition (Japan Patent Office, 2008), formation } \\
\text { and amendment refers to the simplification and unification of } \\
\text { technical specifications, measurement and inspection methods, and } \\
\text { technological terms or symbols.) } \\
\text { 2. 'Negotiations for the drafting of technology standards by } \\
\text { international or domestic committees.' } \\
\text { 3. 'The management and support of standards.' (Japan Patent Office, } \\
\text { 2008) }\end{array}$ \\
\hline
\end{tabular}

Journal of Technology Management for Growing Economies, Volume 4, Number 2, Oct 2013 
Tamura, S.

\begin{tabular}{|l|l|}
\hline Terms & \multicolumn{1}{c|}{ Definition } \\
\hline $\begin{array}{l}\text { Person engaged } \\
\text { in intellectual } \\
\text { property-related } \\
\text { standardisation }\end{array}$ & $\begin{array}{l}\text { PIPRSA is defined as an individual who engages in the following } \\
\text { activities: } \\
\text { activities }\end{array}$ \\
$\begin{array}{l}\text { 1. 'The research of patents for related standards, the evaluation } \\
\text { of license negotiations for essential patents, draft preparation and } \\
\text { submission of patent statements in relation to standardization, } \\
\text { responses to patent infringement claims relating to technology } \\
\text { standards, and standard-related planning, management, research, } \\
\text { evaluation and other activities.' }\end{array}$
\end{tabular}

2. 'The proposal of standards, the standard deliberation process, and domestic and international standard-related negotiation.'

3. 'The supporting activities for standardization, such as education, public promotion, accounting, general affairs, and others.' (Japan Patent Office, 2008).

Person engaged in intellectual property-related activities (PIPRA) PIPRA is defined as an individual who engages in the following activities: 1. 'The acquisition, maintenance, or mining of industrial patents, the management of intellectual property, and the evaluation of intellectual property rights.'

2. 'The negotiation of license agreements, transactions and dispute settlements of intellectual property rights.'

3. 'The support activities necessary for intellectual property-related activities such as planning, investigation, education, accounting, general affairs, and others.'

(Japan Patent Office, 2008).

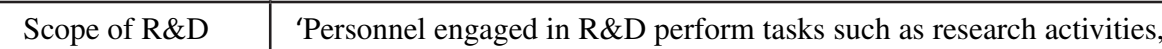
personnel general administrative and accounting work, and all other maintenance work.' (Japan Patent Office, 2008)

R\&D activities

1. 'R\&D activities are carried out in research centers and research departments. R\&D activity includes thinking, considering, and collecting information and materials; testing sampling, experimenting, inspecting, analysing, and reporting results. Other tasks include the preparation of instruments, apparatuses, and other equipment; caring for plants and animals used for experimental purposes; and researching documents.'

2. 'In the case of manufacturing settings such as factories, R\&D activities also include the design, development, manufacture, and evaluation of pilot plants and prototype models.'

3. 'R\&D activity also includes general administrative and accounting work related to R\&D tasks.' (Japan Patent Office, 2008)

Note: Correlation (1) shows the relationship between intellectual property activities and standardisation activities.

Correlation (2) shows the relationship between $R \& D$ activities and intellectual property activities. Correlation (3) shows the relationship between $R \& D$ activities and standardisation activities. 


\section{Dataset and Summary Statistics}

This research paper uses raw data from the SIPRA, which has been published every year since 2002 by the Japan Patent Office. The purpose of this survey (SIPRA) is to provide quantitative data on individuals, companies, universities and research institutes to facilitate IP policy making in Japan. SIPRA focuses on applicants who made five or more applications in Japan for patents and related applications in the previous year. An overview of the sample sizes from the dataset by year and industry is given in Table 2. Because of these definitions and guidelines, the dataset for the SIPRA in 2008 included 2,144 out of 3,375 responses for all organisations. After sorting these 2,144 observations, 219 observations of organisations in the electric machinery industry remained for 2008 .

Tables 2 and 3 show summary statistics for all organisations and for the electric machinery industry in Japan, including the mean values of the numbers of persons engaged in IP-related activities and IP-related standardisation activities and the number of $R \& D$ and patent applications submitted for 2008 . As it can be seen from Table 2, the Japanese electric machinery industry has nearly twice the mean number of patent applications (d) and the number of persons engaged in IP-related activities (a) compared to all industries in Japan. In addition, in 2008 one corporation in the Japanese electric machinery industry had nearly 1.5 times as many persons engaged in IP-related standardisation activities (b) compared with the mean for all industries (d). The mean values for all industries and the electric machinery industry are almost the same for the $R \& D$ activities.

Table 2: Summary statistics for input and output factors in the electric machinery industry and all industries in Japan in 2008

\begin{tabular}{|l|c|c|c|c|}
\hline & $\begin{array}{c}\text { All industries } \\
\text { (mean) } \\
\text { (A) } \\
(\text { sample size } \\
\mathrm{n}=2,144)\end{array}$ & $\begin{array}{c}\text { Electric machinery } \\
\text { industry (mean) } \\
\text { (B) } \\
\text { (sample size } \\
\mathrm{n}=319)\end{array}$ & $\begin{array}{c}\text { Ratio } \\
\text { (B/A) }\end{array}$ & \\
\hline $\begin{array}{l}\text { Intellectual property-related } \\
\text { activities - Number of PIPRA } \\
\text { per organisation (FTE) }\end{array}$ & 6.1 & 11.4 & 1.8 & (a) \\
\hline $\begin{array}{l}\text { Intellectual property-related } \\
\text { standardisation activities } \\
\text { - Number of PIPRSA per } \\
\text { organisation (FTE) }\end{array}$ & 0.8 & 1.3 & 1.5 & (b) \\
\hline
\end{tabular}

Journal of Technology Management for Growing Economies, Volume 4, Number 2, Oct 2013
Spatial

Visualisation of

Correlations 
Tamura, S.

\begin{tabular}{|l|c|c|c|c|}
\hline $\begin{array}{l}\text { R\&D } \\
\text { Number of R\&D personnel per } \\
\text { organisation (FTE) }\end{array}$ & 306.6 & 283.8 & 0.9 & (c) \\
\hline $\begin{array}{l}\text { (Reference) } \\
\text { Patent applications } \\
\text { per organisation }\end{array}$ & 85.6 & 172.2 & 2.0 & (d) \\
\hline
\end{tabular}

Source: Japan Patent Office (2008)

Table 3: Total number of PIPRA and PIPRSA in the electric machinery industry and in all industries in Japan in 2008

\begin{tabular}{|l|c|c|c|}
\hline & $\begin{array}{c}\text { Total number } \\
\text { of PIPRA } \\
\text { (FTE) }\end{array}$ & $\begin{array}{c}\text { Total number of } \\
\text { PIPRSA (FTE) }\end{array}$ & $\begin{array}{c}\text { Total number of } \\
\text { R\&D } \\
\text { (FTE) }\end{array}$ \\
\hline $\begin{array}{l}\text { Electric machin- } \\
\text { ery industry (A) }\end{array}$ & 5,953 & 484 & 90,548 \\
\hline All industries (B) & 18,457 & 2,296 & 657,412 \\
\hline Ratio (A)/(B) & 0.322 & 0.210 & 0.137 \\
\hline
\end{tabular}

Source: Japan Patent Office (2008)

\section{RESULTS}

\section{Correlation analysis}

Figure 1 shows the relationship between the three factors which is examined in this analysis. The calculated coefficients are listed in Table 4. Correlation coefficients (1), (2) and (3) in Table 5 correspond to the coefficient shown in Figure 1. All coefficients are significant at the under the $0.1 \%$ level.

Table 4: Correlations between IPRA, IPSRA and R\&D activities in the electric machinery industry and in all industries in Japan

\begin{tabular}{|l|l|l|l|l|l|l|}
\hline & & $\begin{array}{l}\text { Intellectual } \\
\text { property-related } \\
\text { activities } \\
\text { (PIPRA) }\end{array}$ & $\begin{array}{l}\text { Intellectual property } \\
\text {-related standardi- } \\
\text { sation activities } \\
\text { (PIPRSA) }\end{array}$ & \multicolumn{2}{|c|}{ R\&D } \\
\hline \multirow{2}{*}{$\begin{array}{l}\text { All indus- } \\
\text { tries }\end{array}$} & PIPRA & 1 & $0.340 * * *$ & $(1)$ & $0.451 * * *$ & $(2)$ \\
\cline { 2 - 7 } & PIPRSA & & 1 & $0.077 * * *$ & $(3)$ \\
\cline { 2 - 7 } & R\&D & & & 1 & & \\
\hline
\end{tabular}

Journal of Technology Management for Growing Economies, Volume 4, Number 2, Oct 2013 


\begin{tabular}{|l|l|l|l|l|l|l|}
\hline & & $\begin{array}{l}\text { Intellectual } \\
\text { property-related } \\
\text { activities } \\
\text { (PIPRA) }\end{array}$ & $\begin{array}{l}\text { Intellectual property } \\
\text {-related standardi- } \\
\text { sation activities } \\
\text { (PIPRSA) }\end{array}$ & & \\
\hline $\begin{array}{l}\text { Electric } \\
\text { machinery } \\
\text { industry }\end{array}$ & PIPRA & 1 & $0.408 * * *$ & $(1)$ & $0.790 * * *$ & $(2)$ \\
\cline { 2 - 7 } & PIPRSA & & 1 & & $0.357 * * *$ & $(3)$ \\
\cline { 2 - 7 } & R\&D & & & 1 & & \\
\hline
\end{tabular}

* significant at 5\%; ** significant at 1\%; *** significant at $0.1 \%$

Note: (1), (2), and (3) correspond to correlations (1), (2), and (3) in Figure 1, respectively.

\section{Correlations for all Industries}

The correlation coefficient between the number of persons engaged in IP-related activities and the number of persons engaged in IP-related standardisation activities has a value of 0.340 which weak and significant at $\mathrm{p}=0.001$. The correlation coefficient between $\mathrm{R} \& \mathrm{D}$ and the number of persons engaged in IP-related activities is 0.451 and shows a weak relationship which is significant at $p=0.001$. The correlation coefficient between $R \& D$ and the number of persons engaged in IP-related standardisation activities is 0.077 , indicating that there is no relationship.

\section{Correlations for the Electric Machinery Industry}

The correlation coefficient between the number of persons engaged in IP-related activities and the number of persons engaged in IP-related standardisation activities is weak at 0.408 and is significant at $\mathrm{p}=0.001$. The correlation coefficient between $R \& D$ and the number of persons engaged in IP-related activities is a strong at 0.79 and is significant at $\mathrm{p}=0.001$. The correlation coefficient between $\mathrm{R} \& \mathrm{D}$ and the number of persons engaged in IP-related standardisation activities is 0.357 , suggesting a weak relationship.

\section{General tendencies for the Electric Machinery Industry and all Industries}

In all the cases presented in Figure 2, the electric machinery industry has higher correlation coefficients than those for all industries in Japan. The correlation coefficients is the highest for (2) followed by (1) and (3) 
Tamura, S.

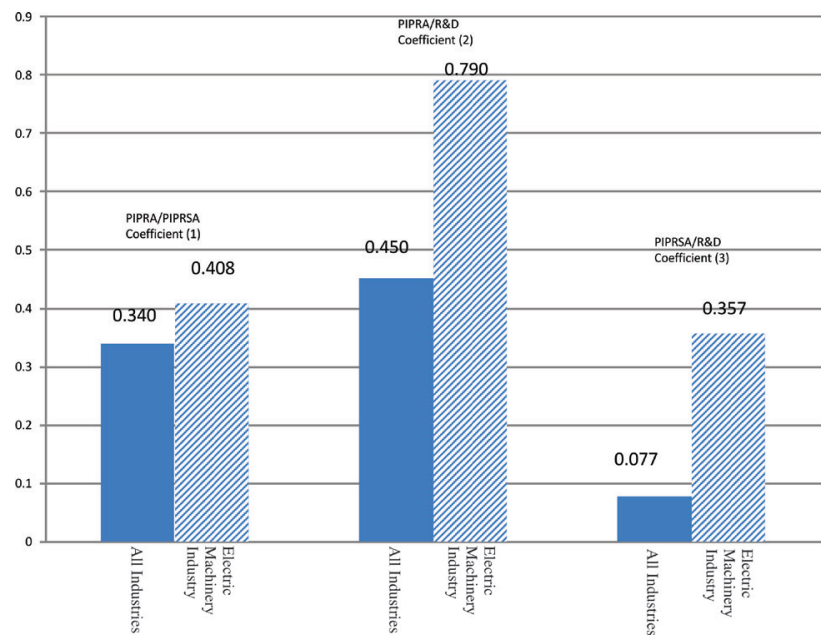

Figure 2: Correlation coefficients in the three-factor model

\section{Distances Among the Three Factors}

To understand the position of these three factors' relationships intuitively, the aforementioned methodology of 'distances' is applied, where

The correlation coefficients are converted to distances as shown in Table 5.

Table 5: Inverse of correlation coefficients between IPRA, IPSRA and R\&D activities in the electric machinery industry and in all industries in Japan

\begin{tabular}{|c|c|c|c|c|c|c|}
\hline \multirow[b]{2}{*}{ All industries } & \multirow[b]{2}{*}{ PIPRA } & \multirow{2}{*}{$\begin{array}{l}\text { Intellectual } \\
\text { property-relat- } \\
\text { ed activities } \\
\text { (PIPRA) } \\
1\end{array}$} & \multicolumn{2}{|c|}{$\begin{array}{l}\text { Intellectual property } \\
\text {-related standardi- } \\
\text { sation activities } \\
\text { (PIPRSA) } \\
\end{array}$} & \multicolumn{2}{|c|}{$\mathrm{R} \& \mathrm{D}$} \\
\hline & & & 2.94 & (1) & 2.22 & (2) \\
\hline & PIPRSA & & \multicolumn{2}{|l|}{1} & 12.98 & (3) \\
\hline & $\mathrm{R} \& \mathrm{D}$ & & & & \multicolumn{2}{|l|}{1} \\
\hline \multirow{3}{*}{$\begin{array}{l}\text { Electric } \\
\text { machinery } \\
\text { industry }\end{array}$} & PIPRA & 1 & 2.45 & (1) & 1.26 & (2) \\
\hline & PIPRSA & & \multicolumn{2}{|l|}{1} & 2.801 & (3) \\
\hline & $\mathrm{R} \& \mathrm{D}$ & & & & \multicolumn{2}{|l|}{1} \\
\hline
\end{tabular}

Note: (1), (2), and (3) correspond to correlations (1), (2), and (3) in Figure 1, respectively.

For comparison purposes, each number is divided by the figure for the $R \& D$ and IP-related activities pair (i.e., correlation coefficient (2)). The distances are thus based upon a standardised distances between R\&D and IP-related

Journal of Technology Management for Growing Economies, Volume 4, Number 2, Oct 2013 
activities with a co-efficient value of 1 . In other words, the value for correlation coefficient (2) is 1 . The three values are relatively calculated as shown in Table 6. These values are comparative distances (CD). This transformation is meaningful because all correlation coefficients are the related to the number of persons.

Table 6: 'Comparative distance' between IPRA, IPSRA and R\&D activity in the electric machinery industry and in all industries in Japan

\begin{tabular}{|c|c|c|c|c|c|c|}
\hline & & $\begin{array}{l}\text { Intellectual } \\
\text { property-related } \\
\text { activities (PIPRA) }\end{array}$ & \multicolumn{2}{|c|}{$\begin{array}{l}\text { Intellectual property } \\
\text {-related standardisation } \\
\text { activities (PIPRSA) }\end{array}$} & \multicolumn{2}{|c|}{$\mathrm{R} \& \mathrm{D}$} \\
\hline \multirow[t]{4}{*}{ All industries } & PIPRA & 0.45 & 1.32 & (1) & 1 & (2) \\
\hline & $\begin{array}{l}\text { PIPR- } \\
\text { SA }\end{array}$ & & \multicolumn{2}{|l|}{0.45} & 5.81 & (3) \\
\hline & $R \& D$ & & & & \multicolumn{2}{|l|}{0.45} \\
\hline & & $\begin{array}{l}\text { Intellectual } \\
\text { property-related } \\
\text { activities (PIPRA) }\end{array}$ & \multicolumn{2}{|c|}{$\begin{array}{l}\text { Intellectual property } \\
\text {-related standardisation } \\
\text { activities (PIPRSA) }\end{array}$} & \multicolumn{2}{|c|}{$\mathrm{R} \& \mathrm{D}$} \\
\hline \multirow{3}{*}{$\begin{array}{l}\text { Electric } \\
\text { machinery } \\
\text { industry }\end{array}$} & PIPRA & 0.79 & 1.944 & (1) & 1 & (2) \\
\hline & $\begin{array}{l}\text { PIPR- } \\
\text { SA }\end{array}$ & & \multicolumn{2}{|l|}{0.79} & 2.22 & (3) \\
\hline & $\mathrm{R} \& \mathrm{D}$ & & & & \multicolumn{2}{|l|}{0.79} \\
\hline
\end{tabular}

\section{Triangle Shapes Among the Three Factors}

Triangles showing the relationships amongst the three factors are shown in Figure 3. In the case of the electric machinery industry, the length between IPrelated activities and IP-related standardisation activities and between $R \& D$ and IP-related standardisation activities is almost the same. Therefore, the triangle is close to being an isosceles triangle. In addition, the comparative distance for IP-related activities and R\&D is shorter as compared to others. For both the electric machinery industry and all industries in Japan, distances are ranked from longest to shortest in the following order: IPRSA/IPRA, IPRSA/ R\&D and R\&D/IPRA.
Spatial

Visualisation of

Correlations 
Tamura, S.

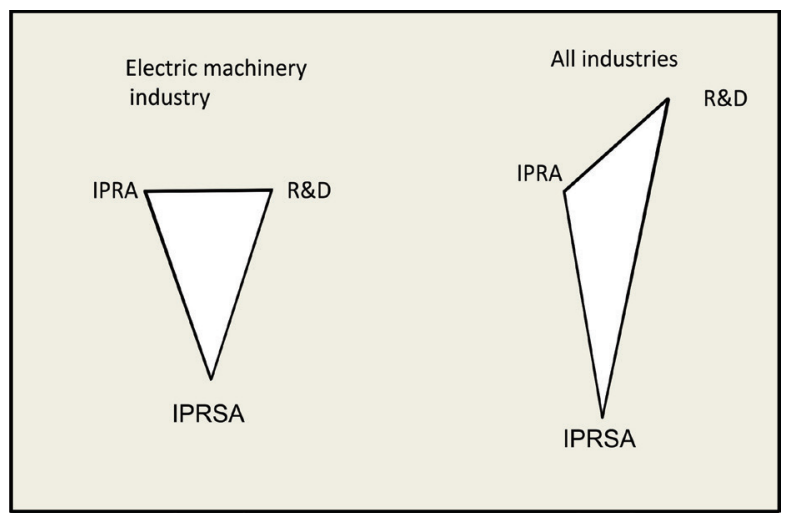

Figure 3. Triangle-shaped model (IPRA, IPSRA and R\&D)

The different triangular shapes reflect the different situations of the electric machinery industry and all industries. R\&D is closer to standardisation in the electric machinery industry. This implies that standardisation is an essential element of R\&D activity.

For all industries, the length of the three sides is unequal. In the electric machinery industry, standardisation plays a key role and its effect on R\&D is larger than in all industries. Standardisation will become larger in all industries as ICT continues to spread.

The value of $\mathrm{RC}$ is a rough measure in terms of the ratio of triangle sizes; the smaller the value, the more compact the triangle. RC shows the comprehensive condition of the three factors.

$$
\begin{gathered}
\mathrm{RC}=\frac{\text { Distance of IPRA and } R \& D \text { in all industries }}{\text { Distance of IPRA and } R \& D \text { in electric machinery industry }} \\
=\frac{1}{\frac{1}{\text { Pearson correlation coef ficient of IP and } R \& D \text { in all industries }}} \\
=\frac{0.451}{0.790}=0.570
\end{gathered}
$$

\section{DISCUSSION}

The results that validate the hypotheses are presented and then additional implications discussed.

\section{Integration amongst three factors: $R \& D$, standardisation and IP}

Hypothesis 1a

The correlation between R\&D and IP-related standardisation activities is significant and positive (Correlation coefficient (3); see Table 4).

Journal of Technology Management for Growing Economies, Volume 4, Number 2, Oct 2013 
The hypothesis is supported in the electric machinery industry, which has a small correlation coefficient of 0.357 . However, the correlation coefficient for all industries is smaller at 0.077 . This result implies that R\&D activities in the Japanese electric machinery industry are associated with standardisation activities. In other words, the distance between R\&D and standardisation is closer in the electric machinery industry than in all industries.

Hypothesis $1 b$

The correlation between R\&D and IP-related activities is significant and positive (Correlation coefficient (2); see Table 4).

This hypothesis is supported for all industries and the electric machinery industry. Moreover, the correlation coefficient is larger in the electric machinery industry(0.790) as compared to all industries (0.451). This implies that the Japanese electric machinery industry is more IP activity-oriented than industries overall. As a concrete example of this fact, it is noted that Japanese companies such as NEC have placed the R\&D and standardisation divisions within the same department (Tamura, 2012a).

Hypothesis 1c

The correlation between IP-related activities and IP-related standardisation activities is significant and positive (Correlation coefficient (1); see Table 4).

This hypothesis is tested to determine whether the relationship between standardisation (IP-related standardisation activities) and IP (IP-related activities)in a three-factor-analysis is different from the two-factor analysis in previous research works. The result is useful to see the consistency between the previously conducted two-factor analysis and the present paper's three-factor analysis.

\section{Graphical representation of distance amongst three factors}

Hypothesis 2

In the Japanese electric machinery industry, the distances between the factors are more equal and the triangle shape of the three factors is more regular than in all industries.

The hypothesis is supported in that the shape of the triangle is more regular for the electric machinery industry than for all industries. To recap, the relationship amongst the key factors for innovation (IP, $R \& D$ and standardisation) is visualised by using the TSM. Standardisation (IP-related standardisation activities) is still positioned far from IP (IP-related activities) and R\&D at this time. The triangle is, hence, isosceles in the electric machinery industry, but is not regular for either all industries or the electric-machinery industry. Considering the rapid spread of standardisation in society, the triangle will likely transform into a regular triangle in the near future; this development will likely take place as shown in Figure 4. This is described as
Spatial

Visualisation of

Correlations 

the degree to which technology standards have spread in industries. This result is supported by the fact that in the electric machinery industry, the number of employees working in standardisation is the largest amongst all industries (Tamura, 2012b). As time progresses, the triangle is likely to change from the all-industries shape to one resembling the electric machinery industry triangle and lastly into a regular triangle. This is understandable as technology standards are likely to spread rapidly to other industries. The factor RC will become smaller, and thus the area of the triangle will decrease and become more compact over time.

\begin{tabular}{|c|c|c|c|}
\hline Timeline & Future & Present & Past \\
\hline Structure & IPRSA & IPosceles triangle & Scalene triangle \\
\hline \multirow[t]{2}{*}{$\begin{array}{l}\text { Distance from } \\
\text { standardisation }\end{array}$} & small & & large \\
\hline & $\begin{array}{l}\text { Correlations between } \\
\text { IPRSA/R\&D, and } \\
\text { between IPRSA/IPRA } \\
\text { are same. Distances } \\
\text { are almost same. }\end{array}$ & $\begin{array}{l}\text { Correlations between } \\
\text { IPRSA/R\&D, and } \\
\text { between IPRSA/IPRA } \\
\text { are same. } \\
\text { Distance between } \\
\text { R\&D/IPRA is closer } \\
\text { than others. }\end{array}$ & $\begin{array}{l}\text { Distance between } \\
\text { IPRSA/R\&D, } \\
\text { IPRSA/IPRA and } \\
\text { R\&D/IPRA are all } \\
\text { different. }\end{array}$ \\
\hline
\end{tabular}

Figure 4: Triangle-shaped development model (TSDM)

\section{Practical Implications}

This study suggests the graphical expression of the relationship amongst the factors. This graphical model is useful for both scholars and practitioners in understanding these relationships. For example, by making time differential development with computer graphics, the triangle relationship can be shown as an animated graph when the data is sufficiently accumulated in the future. Such use will be helpful in discussing innovation management from the viewpoint of standardisation. The visualisation methodology is provided not only for carrying out practical applications, but also for building the academic infrastructure in this field of study.

In addition, the method of triangle-shaped graph expression is useful for coordinating related sections in corporations such as R\&D sections, IP sections and standardisation sections when deciding on whether to participate in SDO activities. Research on the European Union shows that SDO participants have significant fear of unintentional spill-over of R\&D information during SDO meetings (Blind, 2006).However, in the case of the United States, prior research has shown that corporations can gain useful information for patents from SDO activities (Gandal et al, 2007). Hence, for maximising the benefits 
to corporate $\mathrm{R} \& \mathrm{D}$, IP and standardisation resources requires a comprehensive and robust strategy among the three related department in corporations. However, the relationship among the three areas is usually too complex for corporate management teams to understand intuitively the impact of SDO participation. Therefore, tools for facilitating information exchange among the three sections are necessary. Nevertheless, to date no such tool exists that can convert the numerical relation of the three factors to a visual format. Thus, strategic management and communication of the three factors are difficult at present.

To deal with these management issues, the TSM is a useful tool. Under the proposed method, if $R \& D$ and standardisation are not closer than $R \& D$ and IP in the TSM expression, the corporation does not need to be concerned about participation in standardisation activities (e.g., the case of scalene triangle in Figure 4). However, in the case of a regular shaped triangle, where the distance between standardisation and R\&D information becomes short, participation to SDOs must be carefully considered from all corporate perspectives, rather than only one section's perspective, such as standardisation department. For such cases, decision-making by top-level management is essential. This visualisation technique will be helpful for decision making by management.

\section{CONCLUSIONS}

From the above analysis, the following points indicate the novel aspects of this paper.

First, a visualisation model, which describes the relationships amongst IP activities, standardisation activities and R\&D activities, is proposed. The model represents the three factors' relationships in a triangle shaped model. In the electric machinery industry, the shape is an isosceles triangle, but in for all industries the triangle is scalene. For visualisation, the notion of 'distance' is introduced and defined.

In addition, the notion of $\mathrm{RC}$ is introduced to compare general tendencies by industry. In the electric machinery industry, $\mathrm{RC}$ is 0.57 . This value means that the triangle is more compact for the electric machinery industry than for all industries as $0.57<1$.

Secondly, these three factors (R\&D activities, standardisation activities and IP activities) in the electric machinery industry are significantly associated, based on the number of persons engaged in these activities. In particular, standardisation-related activities have a positive relation with R\&D activities in the Japanese electric machinery industry.

Thirdly, spatial relations in the TSM suggest that the triangle will gradually become more regular as the influence of standards spreads through society.

Journal of Technology Management for Growing Economies, Volume 4, Number 2, Oct 2013
Visualisation of

Correlations 


\section{Implications of Differing Shapes}

The distance between the two factors is interpreted as the closeness of information and work within the same organisation or entity. In particular, the distance between R\&D and the other two factors should be watched carefully for the protection of R\&D information. From Figure 4, it can be seen that the more compact the shape is in TSM, it implies more concern which corporations should have for the unintentional spillover of knowledge of $R \& D$ activities since the information of these factors becomes more similar. From the perspective of standardisation factors, the unintentional spillover of knowledge in SDOs becomes highly possible in cases where the triangle is more compact or regular in shape or in cases where the distance between standardisation and R\&D is close. Hence, the triangle shape will help corporations to identify the risk of knowledge spillover.

\section{Summary}

This research suggests a methodology to overcome the communication difficulties regarding standardisation and to improve decision-making on whether or not to participate in SDO activities from comprehensive technology management perspective using visual information. Standardisation is an important element of domestic and international R\&D. Needless to say, today standardisation is an international issue because ICT is influential beyond national borders and international agreements are inevitable for standardised settings. Hence, knowledge development and the transmission of information on standards using visualisation will be a meaningful contribution to international knowledge development worldwide. In addition, technology management of $R \& D$ information relating to standardisation activities in SDOs will be an essential component of corporate technology management in the coming decades. The methodology discussed in this paper needs further elaboration, but its contribution to the technology management issues and the stream of research will be notable.

\section{LIMITATIONS}

This study focuses on corporate activity in the Japanese electric machinery industry. To validate the results, research in other countries is needed. However, the results may be compromised as Japanese companies have many branches across the world. Today, many Japanese corporations have multinational operations, so international aspects could also be captured in the results.

Journal of Technology Management for Growing Economies, Volume 4, Number 2, Oct 2013 
ABBREVIATIONS

CD: Comparative Distance

FTE: Full-Time Equivalent

IP: Intellectual Property

IPRA: IP-Related Activities

IPRSA: IP-Related Standardisation Activities

PIPRA: Number of Persons engaged in IP-Related Activities

PIPRSA: Number of Persons engaged in IP-Related Standardisation Activities

PSRA: Number of Persons engaged in Standardisation-Related Activities

RC: Relative Correlation

SDO: Standard Development Organisation

SIPRA: Survey of IP-Related Activities

SRA: Standardisation-Related Activities

TSDM: Triangle-Shaped Development Model

TSM: Triangle-Shaped Model

\section{ACKNOWLEDGEMENT}

The study was financially supported by a grant from Waseda University, Tokyo. The author appreciates the effort of the editors of JTMGE. Any remaining errors are those of the author.

\section{REFERENCES}

Acs, Z. J. and Audresch, D. B. (1989) 'Patents as a Measure of Innovative Activity', Kyklos, 42: 2, pp. 171-180. http://dx.doi.org/10.1111/j.1467-6435.1989.tb00186.x.

Baba, Y. and Nobeoka, K.(1998) 'Towards Knowledge-based Product Development: The 3-D CAD Model of Knowledge Creation', Research Policy, 26:6, pp. 643-659. http://dx.doi. org/10.1016/S0048-7333(97)00040-1.

Blind, K. (2006) 'Explanatory factors for participation in formal standardization process: Empirical evidence at firm level', Economics of Innovation and New Technology, 15:2, pp.157-170. http://dx.doi.org/10.1080/10438590500143970.

David, P. A. (1985) 'Clio and the Economics of QWERTY', American Economic Review, 75: 2, pp. 332-339.

Gandal, N., Gantman, N. and Genesove, D. (2007) 'Intellectual Property and Standardisation Committee Participation in the US Modem Industry', in Greenstein, S. and Stango, V. Standards and Public Policy, New York, Cambridge University Press, pp. 208-229.

Gay, G. and Dousset, B.(2005) 'Innovation and Network Structural Dynamics: Study of the Alliance Network of a Major Sector of the Biotechnology Industry', Research Policy, 34:10, pp. 1457-1475. http://dx.doi.org/10.1016/j.respol.2005.07.001.

Jaffe, A.B. (1986) 'Technological Opportunity and Spillover of R\&D: Evidence from Firms' Pat-
Spatial

Visualisation of

Correlations 
Tamura, S. ents, Profits and Market Value', American Economic Review, 76:5, pp. 984-999. http://dx.doi. org/10.3386/w1815.

Jaffe, A.B. and Trajtenberg, M. (2002) Patents, Citations \& Innovations, Cambridge, MA, MIT press, pp. 57-62.

Japan Patent Office (2008) Results of the Survey of Intellectual Property-related Activities 2007, Tokyo, Japan Patent Office (in Japanese).

Kohmoto,K., Yoshida,J. and Tanabe,K.(2009) 'Tokkyojoouhouwokatuyousitaseifukennkyuukaihatutoushi no kouka no haakuhouhounikansurukenkyuu' [Research on the Measurement Methodology of Government R\&D Investment Effect by Patent Information], paper presented at The Japan Society for Science Policy and Research Management, Asia University, 24 October, Tokyo (in Japanese).

Lohse, J., Rueter, H., Biolsi, K. and Walker, N. (1990) 'Classifying Visual Knowledge Representations: A Foundation for Visualization Research', Proceedings of the $1^{\text {st }}$ Conference on Visualization '90 (VIS '90), IEEE Xplore database. http://dx.doi.org/10.1109/VISUAL.1990.146374.

Ma, K. (2007) 'Creating a Collaborative Space to Share Data, Visualization, and Knowledge', SIGGRAH Computer Graphics, 41: 4 . http//dx.doi.org/10.1145/1331098.1331105.

Ministry of Economy, Trade and Industry (METI) and Mitsubishi Research Institute (2009) 'Sentangizyutubunya niokerugizyutukaihatu to hyouzyunka no kankeimondainikansuruchousahoukokusyo' [Report on Research on the Relationship and Issues Between Technology Development and Standards in the Field of Advanced Technologies] (online) (cited 26 February 2010). Available from <URL: http://www.jisc.go.jp/policy/kenkyuukai/ipr/ipr houkoku. $\underline{\mathrm{html}}>$ (in Japanese).

Organisation for Economic Co-operation and Development (OECD) (2002) 'Frascati Manual 2002: Proposed Standard Practice for Surveys on Research and Experimental Development', Paris, OECD.

Roijakkers, N. and Hagedoorn, J. (2006) 'Inter-firm R\&D Partnering in Pharmaceutical Biotechnology Since 1975: Trends, Patterns, and Networks', Research Policy, 35:3, pp. 431-446. http://dx.doi.org/10.1016/j.respol.2006.01.006.

Stango, V. (2004), 'The Economics of Standards Wars', Review of Network Economics, 3:1, pp. 1-19. http://dx.doi.org/10.2202/1446-9022.1040,

Steinfield, C., Wigand, R., Markus, M. and Minton,G. (2007) 'Promoting E-business through Vertical IS Standards: Lessons from the US Home Mortgage Industry', in Greenstein, S. and Stango, V. Standards and Public Policy, New York, Cambridge University Press, pp. 160-207.

Tamura, S. (2010) 'Correlation between Standardization and Innovation from the Viewpoint of Intellectual Property Activities: Electric Machinery Industry and All Organizations in Japan', Proceedings of the Conference of Portland International Conference on Management of Engineering and Technology 10 (PICMET10), Thailand, IEEE Xplore database.

Tamura, S. (2012a) 'Effects of Integrating Patents and Standards on Intellectual Property Management and Corporate Innovativeness in Japanese Electric Machinery Corporations', International Journal of Technology Management, 59: 3/4, pp.180-202. http://dx.doi.org/10.1504/ IJTM.2012.047242.

Tamura, S. (2012b), 'Quantitative Measurement of Standardization Activities in Organizations', paper presented at the Fourth International Workshop Evaluation of Technology and Standards, April, Tokyo.

Tamura, S. and Matsuda, H. (2008) 'Policy Action for Strategic International Standardization' [Kokusai hyoujunSenryakunikakawaruseisakutekitorikumi], Journal of the Japanese Society of Precision Engineering, 74:1, pp. 12-15 (in Japanese). http://dx.doi.org/10.2493/ jjspe.74.12.

Journal of Technology Management for Growing Economies, Volume 4, Number 2, Oct 2013 
Tokumasu, S. and Watanabe, C. (2008) 'Institutional Structure Leading to the Similarity and Disparity in Innovation Inducement in EU 15 Countries-Finnish Conspicuous Achievement Triggered by NOKIA's IT Driven Global Business', Journal of Services Research, 8:1, pp. $5-42$.

Dr. Suguru Tamura, Waseda University, Tokyo, Japan. Email: suguru. tamura@nifty.com. 